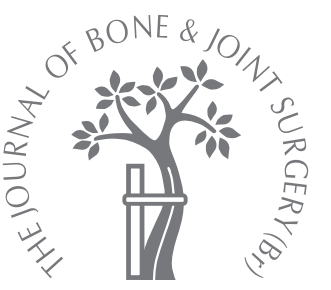

G. Grammatopoulos, H. Pandit, Oxford Hip and Knee Group, D. W. Murray, H. S. Gill

From University of Oxford, Oxford, United Kingdom

\title{
The relationship between head-neck ratio and pseudotumour formation in metal-on- metal resurfacing arthroplasty of the hip
}

\author{
Pseudotumour is a rare but important complication of metal-on-metal hip resurfacing that \\ occurs much more commonly in women than in men. We examined the relationship \\ between head-neck ratio (HNR) and pseudotumour formation in 18 resurfaced hips \\ (18 patients) revised for pseudotumour and 42 asymptomatic control resurfaced hips \\ (42 patients).
}

Patients in whom pseudotumour formation had occurred had higher pre-operative HNR than the control patients (mean 1.37 (SD 0.10) vs mean 1.30 (SD 0.08) p=0.001). At operation the patients with pseudotumours had a greater reduction in the size of their femoral heads ( $p=0.035$ ) and subsequently had greater neck narrowing (mean 10.1\% (SD 7.2 ) vs mean $3.8 \%$ (SD 3.2) $\mathrm{p}<0.001$ ). No female patient with a pre-operative HNR $\leq 1.3$ developed a pseudotumour.

We suggest that reducing the size of the femoral head, made possible by a high preoperative HNR, increases the risk of impingement and edge loading, and may contribute to high wear and pseudotumour formation. As the incidence of pseudotumour is low in men, it appears safe to perform resurfacing in men. However, this study suggests that it is also reasonable to resurface in women with a pre-operative $H N R \leq 1.3$.

Contemporary metal-on-metal hip resurfacing arthroplasty (HRA) is an established option for the treatment of end-stage osteoarthritis in young adults ${ }^{1}$ with the perceived advantage of restoration of hip joint anatomy. ${ }^{2}$ However, it has recently been suggested that there is a reduction in head-neck ratio (HNR) following resurfacing arthroplasty. ${ }^{3}$ Most studies have ignored the femoral head articular cartilage, which can be up to $2.6 \mathrm{~mm}$ thick $^{4}$ and therefore contributes to the real HNR. A decrease in HNR may restrict the range of movement and probably increases the risk of impingement.

Registry data suggest that the mid-term failure rate in HRA is increased compared to conventional total hip replacement (THR), especially in women. ${ }^{5}$ Causes of failure include fracture of the femoral neck, avascular necrosis, loosening, infection ${ }^{6}$ and pseudotumours. ${ }^{7}$ Additionally subsequent narrowing of the femoral neck is well recognised, but the aetiology and significance remains unknown. ${ }^{8,9}$

Pseudotumours are a rare but important complication of HRA. Our previous investigation suggested that they occur in about $1 \%$ or $2 \%$ of patients, ${ }^{10}$ and symptoms can be severe, often leading to revision. ${ }^{11}$ Risk factors for pseudotumour include female gender, hip dysplasia, age $<40$ years and small components. ${ }^{10}$ Pseudotumour formation is usually a reaction to increased wear debris, ${ }^{12,13}$ which may be a consequence of impingement and/or edge loading. ${ }^{14}$ Both processes are influenced by design, component position, mechanical factors and patient variables. ${ }^{14-16}$ Acetabular component malposition has been shown to have a role in pseudotumour development, however pseudotumours can occur with wellorientated components, ${ }^{17}$ suggesting that other factors are contributing to the process.

A small amount of narrowing of the femoral neck tends to occur in the majority of resurfaced hips, with a resultant increase in the HNR. Up to $25 \%$ of resurfaced hips are thought to have $>10 \%$ narrowing, occurring mainly in the first two to three years postoperatively. ${ }^{1}$ Interestingly, the risk factors associated with neck narrowing are similar to those for pseudotumour formation. ${ }^{1}$

The literature is inconsistent about how the $\mathrm{HNR}$ is measured. In the native hip, it is generally considered to be the ratio of the diameter of the femoral head to the minimum width of the femoral neck, which we will term HNR. ${ }^{3}$ In contrast, after HRA, it is considered to be the ratio of diameter of the femoral head to the 
Table I. The characteristics of the patients in the pseudotumour and control groups. Numbers are given on a per-case basis

\begin{tabular}{|c|c|c|c|c|}
\hline & & Age (yrs) & Diagnosis & $\begin{array}{l}\text { Follow-up/ } \\
\text { revision time (yrs) }\end{array}$ \\
\hline & Gender (n) & Mean (range) & OA/dys ${ }^{*}$ & Mean (range) \\
\hline \multirow[t]{3}{*}{ Pseudotumour } & All $(n=18)$ & $53.0 \quad(28.7$ to 67.1$)$ & $16 / 2$ & $3.6(0.9$ to 8.3$)$ \\
\hline & Men $(n=4)$ & 48.6 ( 40.6 to 54.3 ) & $4 / 0$ & 5.4 (3.0 to 8.3 ) \\
\hline & Women $(n=14)$ & 54.2 (28.7 to 67.1 ) & $12 / 2$ & $3.1(0.9$ to 6.6$)$ \\
\hline \multirow[t]{3}{*}{ Control } & All $(n=42)$ & 55.1 (29.9 to 68.1$)$ & $36 / 6$ & $2.8(0.6$ to 7.3$)$ \\
\hline & $\operatorname{Men}(n=5)$ & 55.5 (47.2 to 68.1$)$ & $5 / 0$ & $2.8(0.8$ to 3.8$)$ \\
\hline & Women $(n=37)$ & 55.0 (29.9 to 67.4$)$ & $31 / 6$ & $2.9(0.6$ to 7.3$)$ \\
\hline
\end{tabular}

* OA/dys, osteoarthritis/dysplasia

diameter of the neck at the head-neck junction, which we will term the head junction ratio $(\mathrm{HJR}){ }^{8}$

The aims of this study were to measure the head-neck ratio before and after HRA and to examine the association between pseudotumour and changes in head-neck ratio.

\section{Patients and Methods}

We included the first 26 consecutive HRAs (25 patients) revised for pseudotumour in our unit. The majority of these patients have been reported previously. ${ }^{7,8,17}$ The diagnosis of pseudotumour was made on the basis of clinical, radiological, intra-operative and histological findings. We aimed to match each hip in which a pseudotumour had occurred with two asymptomatic HRAs from our entire cohort of patients with HRAs (1502 hips, 1313 patients), in order to increase statistical power. Controls were matched for the known risk factors for pseudotumour formation: gender, age, pre-operative diagnosis and component size, as well as duration of follow-up. In order to investigate the changes over time, a minimum of the pre-operative, post-operative and prerevision surgery or most recent follow-up radiographs had to be available. Complete sets of radiographs were only available for 18 hips (18 patients) with pseudotumour (pseudotumour group) and 42 control hips (42 patients, control group). Implants from three manufacturers were involved: Birmingham Hip Resurfacing ( $\mathrm{n}=11$, Smith \& Nephew, Birmingham, United Kingdom), Conserve Plus ( $\mathrm{n}=6$, Wright Medical Technology, Memphis, Tennessee), and ReCap ( $\mathrm{n}=1$, Biomet, Warsaw, Indiana). The mean time to revision was 3.6 years $(0.9$ to 8.3$)$. The mean follow-up for controls was 2.8 years (0.6 to 7.3) (Table I). Measurements. All the radiographs were measured twice by one author (GG), who was blinded to group and time sequence and the mean value from the two sets of measurements was used for subsequent analysis. The intra-class correlation coefficient (ICC) for the two sets of measurements was 0.982 (95\% confidence interval (CI) 0.976 to 0.987). A subset of the measurements $(\mathrm{n}=18)$ were repeated by a second observer (HP) to establish the interclass correlation for these measurements, which was 0.940 (95\% CI 0.848 to 0.977 ).

Pre-operative HNR $\left(\mathrm{HNR}_{\text {pre }}\right)$, based on the bony outline of the head, was measured using the method of Doherty et al. ${ }^{18}$ A line was defined between the centre of the femoral head and the centre of the femoral neck at its narrowest section. The maximum diameter of the femoral head perpendicular to this line was measured, and in a similar manner the minimum diameter of the proximal femoral neck was measured. The measurements from the post-operative $\left(\mathrm{HNR}_{\text {post }}\right)$ and pre-revision/follow-up radiographs $\left(\mathrm{HNR}_{\text {follow }}\right)$ were made with the femoral component being measured instead of the femoral head. Assuming the cartilage layer was $2 \mathrm{~mm}$ thick $(4 \mathrm{~mm}$ increase in diameter), ${ }^{4}$ the HNR based on the diameter of the head, including the articular cartilage pre-operatively $\left(\mathrm{HNR}_{\mathrm{art}}\right)$, was calculated. During the operation, as the minimal neck diameter did not change, the change in head size can be calculated from the change in HNR.

The HJR measurements were also made using the postoperative and pre-revision/follow-up radiographs. The method used was similar to that used for HNR, except that the width of the neck was measured at the junction of the neck with the femoral component, as previously described. ${ }^{8}$ The difference in the HJR measurements made from postoperative and follow-up radiographs allowed us to calculate the degree of narrowing of the neck at the base of the component, which we termed junction narrowing.

The radiographic anteversion and inclination of each acetabular component were measured using Ein-Bild Roentgen Analyse (EBRA). ${ }^{19}$

Analyses. Differences in HNR pre-operatively, postoperatively and at revision/follow-up were examined using the non-parametric Wilcoxon's signed-ranks test.

The immediate changes in HNR as a result of the operation can be expressed relative to either the pre-operative HNR, based on the measurement of the bony dimensions, or the addition of the articular cartilage thickness. Similarly, the changes between post-operative and follow-up were expressed as changes in both HNR and HJR. 
Table II. Changes in head-neck ratio (HNR) and headjunction ratio (HJR) for all hips included in the study

\begin{tabular}{lll}
\hline HNR/HJR & Gender (n) & Mean (range) \\
\hline HNR $_{\text {art }}$ & All (60) & $1.44(1.19$ to 1.65$)$ \\
& Male (9) & $1.33(1.19$ to 1.48$)$ \\
& Female (51) & $1.46(1.26$ to 1.65$)$ \\
HNR $_{\text {pre }}$ & All (60) & $1.32(1.09$ to 1.51$)$ \\
& Male (9) & $1.24(1.09$ to 1.37$)$ \\
& Female (51) & $1.38(1.13$ to 1.51$)$ \\
HNR $_{\text {post }}$ & All (60) & $1.33(1.11$ to 1.47$)$ \\
& Male (9) & $1.26(1.11$ to 1.41$)$ \\
& Female (51) & $1.34(1.17$ to 1.46$)$ \\
HNR $_{\text {follow }}$ & All (60) & $1.39(1.17$ to 1.97$)$ \\
& Male (9) & $1.33(1.21$ to 1.58$)$ \\
& Female (51) & $1.4(1.17$ to 1.97$)$ \\
HJR $_{\text {post }}$ & All (60) & $1.26(1.1$ to 1.43$)$ \\
& Male (9) & $1.19(1.11$ to 1.44$)$ \\
& Female (51) & $1.28(1.1$ to 1.4$)$ \\
HJR $_{\text {follow }}$ & All (60) & $1.34(1.16$ to 1.94$)$ \\
& Male (9) & $1.3(1.16$ to 1.59$)$ \\
& Female (51) & $1.35(1.17$ to 1.96$)$ \\
\hline
\end{tabular}

The percentage of neck narrowing $(\mathrm{NN} \%)$ that occurred between the post-operative and follow-up radiographs was calculated as follows:

$$
\mathrm{NN} \%=\frac{1-\mathrm{HNR}_{\text {post }}}{\mathrm{HNR}_{\text {follow }}} \times 100
$$

The percentage junction narrowing $(\mathrm{JN} \%)$ was calculated as follows:

$$
\mathrm{JN} \%=\frac{1-\mathrm{HJR}_{\text {post }}}{\mathrm{HJR}_{\text {follow }}} \times 100
$$

The correlations between changes in HNR and $\mathrm{HNR}_{\text {pre }}$ were examined using Spearman's rank correlation coefficient. Changes in HNR and HJR at the various time points were examined on a gender and group basis using the nonparametric Mann-Whitney U test. Differences between the two groups in acetabular anteversion and inclination were also examined using the Mann-Whitney U test.

The power of $\mathrm{HNR}_{\text {pre }}$ and the change of $\mathrm{HNR}_{\mathrm{art}}$ to the $\mathrm{HNR}_{\text {post }}$ for predicting pseudotumour development were examined by receiver operating characteristic (ROC) analyses performed both for the whole cohort and considering women only. Finally, this analysis was performed for the whole cohort to examine the diagnostic power of JN\% in

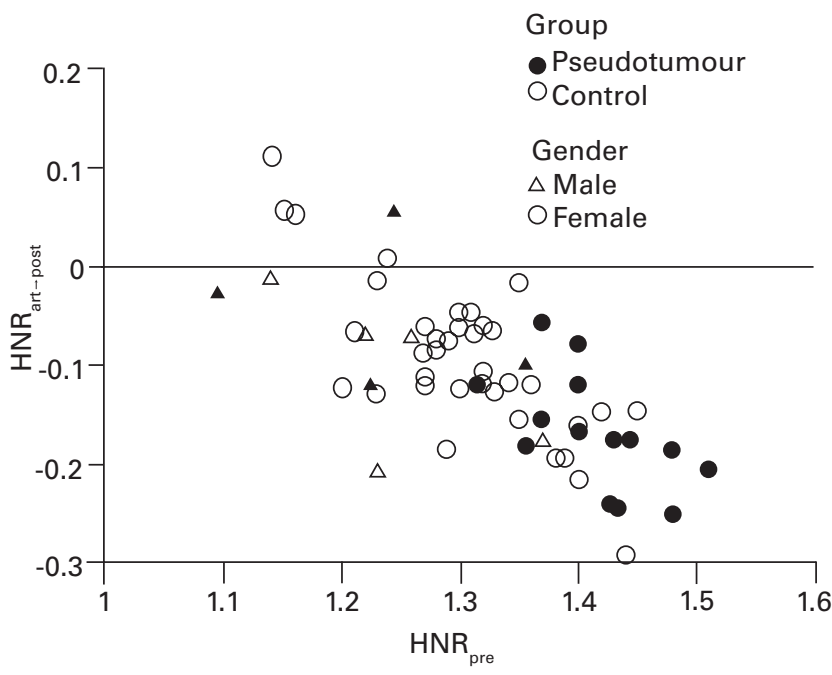

Fig. 1

Scatter plot of pre-operative head-neck ratio (HNR) versus change in HNR from $\mathrm{HNR}_{\text {art }}$ to $\mathrm{HNR}_{\text {post }}\left(\mathrm{HNR}_{\text {art } \rightarrow \text { post }}\right)$.

detecting pseudotumour formation. The area under the curve (AUC) is an indication of predictive power: a perfect predictor has a curve $=1.0$, whereas that no better than random chance has a curve $=0.5 .{ }^{20}$ Statistical significance was defined as a p-value $\leq 0.05$.

\section{Results}

Entire cohort findings. The mean $\mathrm{HNR}_{\text {pre }}$ was 1.32 (SD 0.09) and the mean $\mathrm{HNR}_{\text {art }}$ was 1.44 (SD 0.10). The mean $\mathrm{HNR}_{\text {post }}$ was 1.33 (SD 0.07); this was no different from $\mathrm{HNR}_{\text {pre }}(\mathrm{p}=0.494)$, but was significantly $(\mathrm{p}<0.001)$ smaller than $\mathrm{HNR}_{\text {art }}$ (Table II). By the time of revision or follow-up, the HNR had increased significantly $(\mathrm{p}<0.001)$, with mean $\mathrm{HNR}_{\text {follow }}$ being 1.39 (SD 0.12). The latter was significantly $(\mathrm{p}<0.001)$ larger than $\mathrm{HNR}_{\text {pre }}$, but significantly $(\mathrm{p}<0.001)$ smaller than $\mathrm{HNR}_{\mathrm{art}}$. Similarly, HJR had increased significantly $(\mathrm{p}<0.001)$ at follow-up, with the mean $\mathrm{HJR}_{\text {post }}$ being 1.26 (SD 0.07) and the mean $\mathrm{HJR}_{\text {follow }}$ increasing to 1.34 (SD 0.12). The mean proportional junction narrowing between the post-operative value and follow-up was $5.7 \%$ (SD 5.6).

The changes in HNR were significantly $(\mathrm{p}<0.001)$ negatively correlated to $\mathrm{HNR}_{\text {pre }}$ (Fig. 1), with the correlation being greater when the articular cartilage thickness was included $(r=-0.69)$ than when the bony dimension was used $(r=-0.61)$.

Entire cohort: differences between genders. Both pre-operative measures of HNR were significantly larger for the women than for the men: $\mathrm{HNR}_{\text {pre }}$ was 1.33 (SD 0.09) for women compared to 1.24 (SD 0.09) for men ( $\mathrm{p}=0.006$ ), and $\mathrm{HNR}_{\text {art }}$ was 1.46 (SD 0.09) for women compared to 1.33 (SD 0.09) for men ( $\mathrm{p}=0.003)$ (Table II). The significant difference in HNR between women and men was maintained post-operatively $(\mathrm{p}=0.008)$, with $\mathrm{HNR}_{\text {post }}$ being 1.34 
Table III. Comparison of changes in head-neck ratio (HNR) values between pseudotumour (PT) and control groups

\begin{tabular}{|c|c|c|c|c|c|c|c|c|}
\hline \multirow[b]{2}{*}{ Group } & \multicolumn{2}{|l|}{ HNR $_{\text {art }}$} & \multicolumn{2}{|c|}{ HNR $_{\text {pre }}$} & \multicolumn{2}{|c|}{ HNR $_{\text {post }}$} & \multicolumn{2}{|c|}{ HNR $_{\text {follow }}$} \\
\hline & \multicolumn{2}{|c|}{ Mean (range) } & \multicolumn{2}{|c|}{ Mean (range) } & \multicolumn{2}{|c|}{ Mean (range) } & \multicolumn{2}{|c|}{ Mean (range) } \\
\hline \multicolumn{9}{|l|}{$\overline{\mathrm{PT}}$} \\
\hline All (18) & 1.49 & (1.19 to 1.65$)$ & 1.37 & (1.10 to 1.51$)$ & 1.35 & (1.16 to 1.46$)$ & 1.47 & (1.21 to 1.97$)$ \\
\hline Male (4) & 1.33 & (1.19 to 1.46$)$ & 1.23 & (1.10 to 1.36$)$ & 1.29 & (1.16 to 1.41$)$ & 1.41 & (1.21 to 1.58$)$ \\
\hline Female (14) & 1.54 & (1.43 to 1.65$)$ & 1.42 & (1.32 to 1.51$)$ & 1.37 & (1.29 to 1.46$)$ & 1.48 & (1.29 to 1.97$)$ \\
\hline \multicolumn{9}{|l|}{ Controls } \\
\hline All (42) & 1.41 & (1.23 to 1.60$)$ & 1.3 & (1.14 to 1.45$)$ & 1.32 & (1.11 to 1.30$)$ & 1.35 & (1.17 to 1.53 ) \\
\hline Male (5) & 1.34 & (1.23 to 1.48$)$ & 1.24 & (1.14 to 1.37$)$ & 1.23 & $(1.11$ to 1.30$)$ & 1.28 & (1.22 to 1.33 ) \\
\hline Female (37) & 1.42 & (1.26 to 1.60$)$ & 1.3 & (1.14 to 1.45$)$ & 1.33 & (1.17 to 1.45$)$ & 1.36 & (1.17 to 1.53$)$ \\
\hline All PT vs Controls* & 0.001 & & 0.00 & & 0.069 & & 0.001 & \\
\hline Male PT vs Controls* & 0.806 & & 1.000 & & 0.624 & & 0.221 & \\
\hline Female PT vs Controls* & 0.00002 & & 0.00 & & 0.058 & & 0.001 & \\
\hline
\end{tabular}

* Mann-Whitney U test

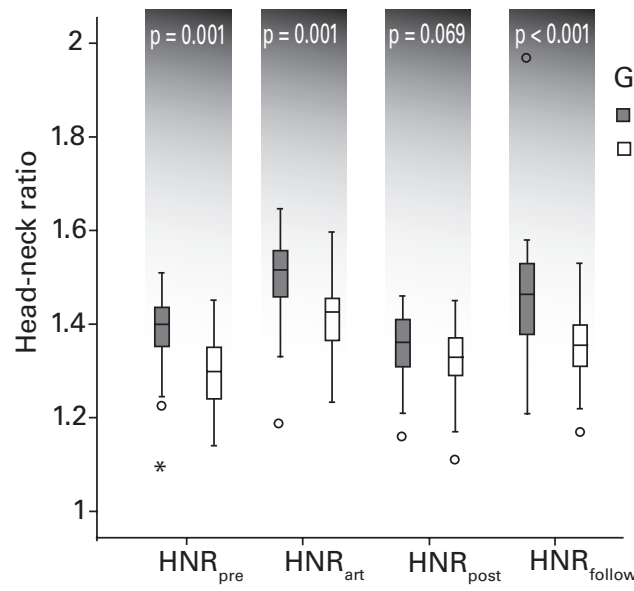

Fig. 2a

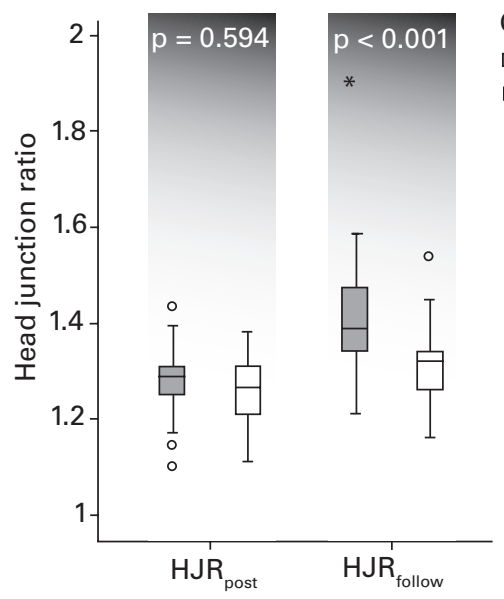

Fig. $2 b$

Box and whisker plots of differences in a) head-neck ratio (HNR) and b) head junction ratio (HJR) between pseudotumour and control groups at various time points. Mann-Whitney $U$ test. The top of the box represents the 75 th, the bottom the 25 th and the line in the middle the 50th percentile. The whiskers represent the highest and lowest values that are not outliers or extreme values. Outliers are represented by ${ }^{*}$, extreme values are represented by o beyond the whiskers.

(SD 0.06) for women and 1.26 (SD 0.09) for men. At followup, women had larger HNR with a mean of 1.40 (SD 0.12), compared to men with a mean of 1.33 (SD 0.12), but this difference was not statistically significant $(\mathrm{p}=0.065)$.

HJR post-operatively was significantly larger $(\mathrm{p}=0.001)$ in women, with a mean of 1.28 (SD 0.06), in comparison to men with a mean of 1.19 (SD 0.06) (Table II). At follow-up, women still had larger HJR, but the difference was not significant $(\mathrm{p}=0.064), \mathrm{HJR}_{\text {follow }}$ being 1.35 (SD 0.12) for women and 1.30 (SD 0.14) for men.

Pseudotumour group versus control group. $\mathrm{HNR}_{\text {pre }}$ was significantly $(\mathrm{p}=0.001)$ larger for the pseudotumour group (mean 1.37, SD 0.10) than for the control group (mean 1.30, SD 0.08) (Table III, Fig. 2). Similarly, with the increased head size by inclusion of the articular cartilage thickness, the $\mathrm{HNR}_{\text {art }}$ was also significantly $(\mathrm{p}=0.001)$ larger for the pseudotumour group (mean 1.49, SD 0.11) than for the control group (mean 1.41, SD 0.08). Postoperatively there was no statistical difference in either $\mathrm{HNR}_{\text {post }}(\mathrm{p}=0.069)$ or $\mathrm{HJR}_{\text {post }}(\mathrm{p}=0.594)$ between the two groups. By the time of follow-up the pseudotumour group had larger $\mathrm{HNR}_{\text {follow }}$ values than the control group (mean 1.47, SD 0.16; mean 1.35, SD 0.08, respectively, $\mathrm{p}=0.001)$. The values of $\mathrm{HJR}_{\text {follow }}$ were also larger for the pseudotumour group (mean 1.42, SD 0.17; mean 1.31, SD 0.07 , respectively, $\mathrm{p}=0.001$ ); correspondingly the proportional junction narrowing was $10.1 \%$ (SD 7.3) for the pseudotumour group compared to $3.5 \%$ (SD 3.1) for the control group $(\mathrm{p}<0.001)$.

In the pseudotumour group $15(83 \%)$ of the hips had $5 \%$ or more junction narrowing, compared to ten $(24 \%)$ of the control group $(\mathrm{p}<0.001)$. A total of six of the pseudo- 
Table IV. Comparison of changes in head-junction ratio (HJR) values between pseudotumour (PT) and control groups

\begin{tabular}{|c|c|c|c|c|}
\hline \multirow[b]{2}{*}{ Group } & \multicolumn{2}{|c|}{ HJR $_{\text {post }}$} & \multicolumn{2}{|c|}{ HJR follow } \\
\hline & \multicolumn{2}{|c|}{ Mean (range) } & \multicolumn{2}{|c|}{ Mean (range) } \\
\hline \multicolumn{5}{|l|}{ PT } \\
\hline All (18) & 1.27 & (1.10 to 1.44$)$ & 1.42 & (1.21 to 1.96$)$ \\
\hline Male (4) & 1.23 & (1.15 to 1.44$)$ & 1.39 & (1.21 to 1.59$)$ \\
\hline Female (14) & 1.29 & (1.10 to 1.40$)$ & 1.43 & (1.22 to 1.96$)$ \\
\hline \multicolumn{5}{|l|}{ Controls } \\
\hline All (42) & 1.26 & (1.11 to 1.38 ) & 1.31 & (1.16 to 1.54$)$ \\
\hline Male (5) & 1.16 & (1.11 to 1.19$)$ & 1.21 & (1.16 to 1.27 ) \\
\hline Female (37) & 1.27 & (1.16 to 1.38 ) & 1.32 & (1.17 to 1.54$)$ \\
\hline All PT vs Controls* & 0.594 & & 0.001 & \\
\hline Male PT vs Controls* & 0.806 & & 0.11 & \\
\hline Female PT vs Controls* & 0.434 & & 0.002 & \\
\hline
\end{tabular}

tumour group had $10 \%$ or more junction narrowing, compared to two $(5 \%)$ of the control group $(\mathrm{p}=0.007)$.

There were no statistical differences between the groups in terms of acetabular anteversion (mean $12.2^{\circ}$ (SD 7.6) mean $15.3^{\circ}$ (SD 7.2), respectively; $\mathrm{p}=0.093$ ) and inclination (mean $49.5^{\circ}$ (SD 11.6) and mean $47.0^{\circ}$ (SD 7.1), respectively; $\mathrm{p}=0.478$ ).

When the two groups were compared on a genderspecific basis, the differences between them were found to be due to differences between women. There were no significant differences between men from the two groups for any of the HNR measures (Table III). However, for the women in the pseudotumour group the $\mathrm{HNR}_{\text {pre, }}, \mathrm{HNR}_{\text {art, }}$, $\mathrm{HNR}_{\text {follow }}$ and $\mathrm{HJR}_{\text {follow }}$ values were significantly higher than for the women in the control group (Table IV). There was no significant difference in $\mathrm{HNR}_{\text {post }}$ nor in $\mathrm{HJR}_{\text {post }}$ between women in either group.

ROC analyses for prediction of pseudotumour formation. Considering both groups, $\mathrm{HNR}_{\text {pre }}$ was significantly $(\mathrm{p}=0.001)$ more predictive than chance (AUC $=0.77,95 \%$ CI 0.62 to 0.92 versus $\mathrm{AUC}=0.5$ for chance) at predicting pseudotumour formation. Performing the same analysis for women only, the AUC for $\mathrm{HNR}_{\text {pre }}$ was 0.89 (95\% CI 0.80 to $0.98, \mathrm{p}<0.001$ ) (Fig. 3). A threshold value of 1.35 for $\mathrm{HNR}_{\text {pre }}$ gave the highest sensitivity $(92.9 \%)$ and specificity $(78.4 \%)$ in predicting pseudotumour formation in women (Table V). $\mathrm{HNR}_{\text {pre }}>1.35$ had a 3.4 times higher risk of developing pseudotumour than those below $(\mathrm{p}<0.001)$. No women with $\mathrm{HNR}_{\text {pre }} \leq 1.3$ developed pseudotumour.

For the whole cohort, the change in the $\mathrm{HNR}_{\text {art, }}$ to the $\mathrm{HNR}_{\text {post }}$ was more predictive than chance (AUC $=0.68,95 \%$ CI 0.52 to $0.82, \mathrm{p}=0.032$ ). When considering women only, the predictive power of this change in HNR was improved (AUC $=0.782,85 \%$ CI 0.64 to $0.92, p=0.002$ ). A threshold value of -0.15 for the change in $\mathrm{HNR}_{\text {art }}$ to $\mathrm{HNR}_{\text {post }}$, which was the equivalent of a $5.3 \mathrm{~mm}$ reduction in the diameter of

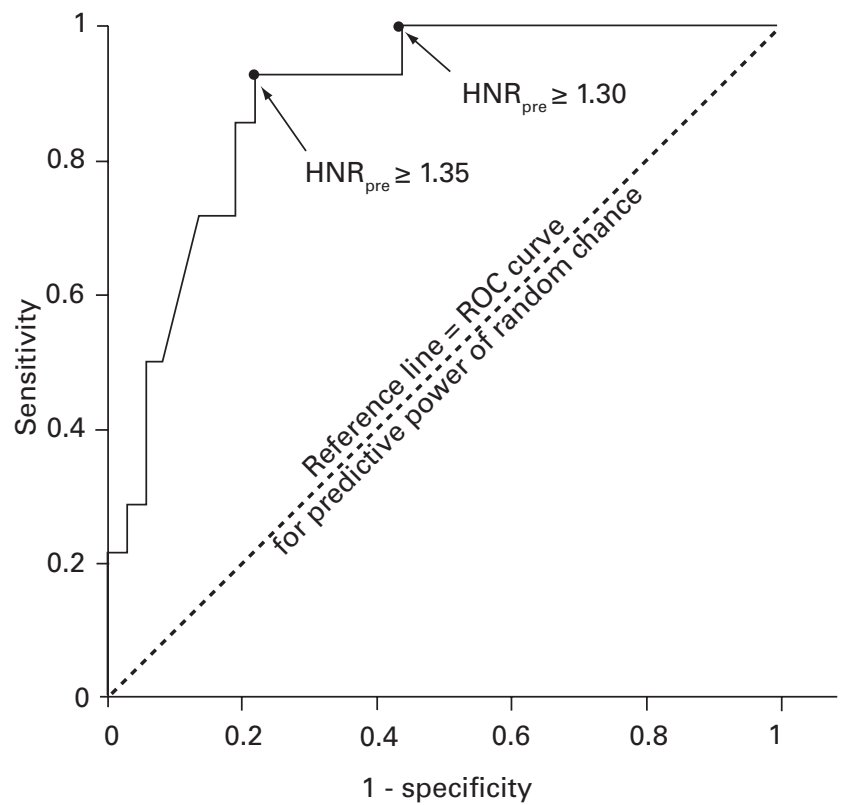

Fig. 3

Received operating characteristic (ROC) curve for women only, examining the power of pre-operative head-neck ratio (HNR) in predicting pseudotumour. The difference between the curve and the reference line demonstrates the substantial predictive power of $H_{N R}$ pre

the femoral head with its articular cartilage, for women gave $71 \%$ sensitivity and $81 \%$ specificity. Women who downsized by more than $5.3 \mathrm{~mm}$ had a 4.4 times higher risk of developing a pseudotumour than those who downsized by less than $53 \mathrm{~mm}(\mathrm{p}<0.001)$.

$\mathrm{JN} \%$ for the whole cohort was significantly $(\mathrm{p}<0.001)$ better than chance at detecting pseudotumour formation (AUC $=0.86,95 \%$ CI 0.77 to 0.95 ). A threshold of $5.1 \mathrm{JN} \%$ gave the highest combination of sensitivity $(83.3 \%)$ and specificity $(76.2 \%)$ for the detection of pseudotumour. A threshold of $10 \%$ gave a $33.3 \%$ sensitivity and $95.2 \%$ specificity.

\section{Discussion}

Impingement after hip replacement will tend to cause the femoral head to sublux within the acetabular component. With a metal-on-metal articulation this will cause edge loading with loss of lubrication and potentially massive wear. The risk of impingement depends on both acetabular and femoral factors as well as hip movements. One of the most important femoral factors influencing when impingement occurs is HNR. Impingement occurs with a small range of movement as the size of the head decreases and the size of the neck increases, both of which are associated with a reduction in HNR. There is a trigonometric relationship between HNR and the angle at which impingement occurs (Fig. 4). From this relationship, for a normal or a resurfaced hip an increase in HNR of 0.1 results in impingement occurring about $5^{\circ}$ later, or 
Table V. Threshold values derived from receiver operating characteristic (ROC) analysis examining the power of pre-operative head-neck ratio $\left(\mathrm{HNR}_{\text {pre }}\right)$ and the change in the HNR from the pre-operative value, includlng articular cartilage thickness, to the post-operative value $\left(H_{N R}\right.$ art $\rightarrow$ post $)$ in women in predicting pseudotumour and of percentage junction narrowing (JN\%) in the whole group in detecting pseudotumour

\begin{tabular}{|c|c|c|c|c|c|c|c|}
\hline Parameter & & Value & Sensitivity (\%) & Specificity (\%) & Risk ratio & Odds ratio & $\begin{array}{l}\text { p-value } \\
\text { (Fisher's exact) }\end{array}$ \\
\hline \multicolumn{8}{|l|}{ Women only } \\
\hline \multirow[t]{2}{*}{$\mathrm{HNR}_{\text {pre }}$} & ROC threshold & 1.35 & 92.9 & 78.4 & 3.43 & 35.1 & $<0.001$ \\
\hline & Clinically optimal threshold & 1.3 & 100 & 52.5 & 1.77 & Infinity & 0.002 \\
\hline $\mathrm{HNR}_{\text {art } \rightarrow \text { post }}$ & ROC threshold & -0.15 & 71.4 & 81.1 & 3.78 & 10.71 & $<0.001$ \\
\hline \multicolumn{8}{|l|}{ Whole cohort } \\
\hline \multirow[t]{2}{*}{ JN\% } & ROC threshold & 5.1 & 83.3 & 76.2 & 3.5 & 16.0 & $<0.001$ \\
\hline & Clinically optimal threshold & 10 & 33.3 & 95.2 & 7.0 & 10.0 & 0.007 \\
\hline
\end{tabular}

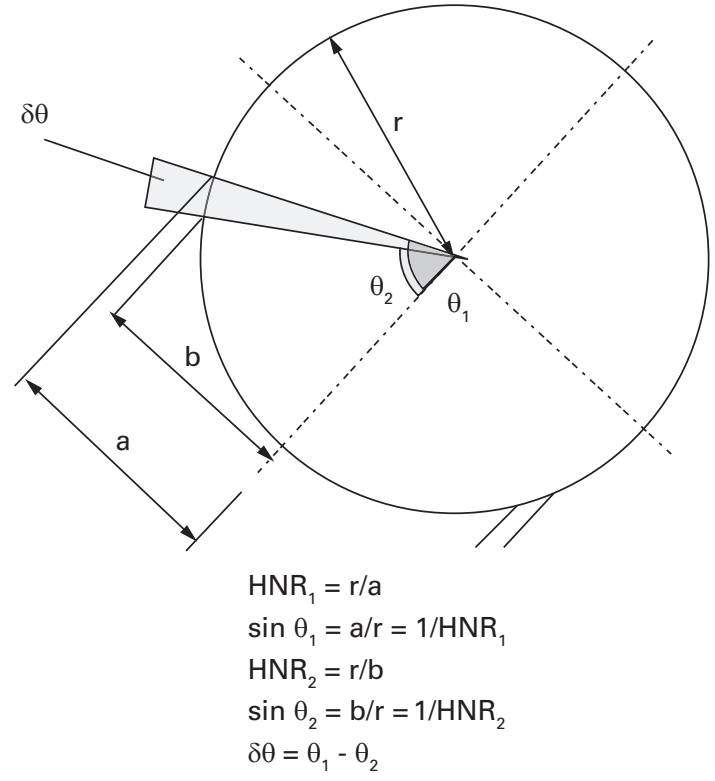

Fig. 4a

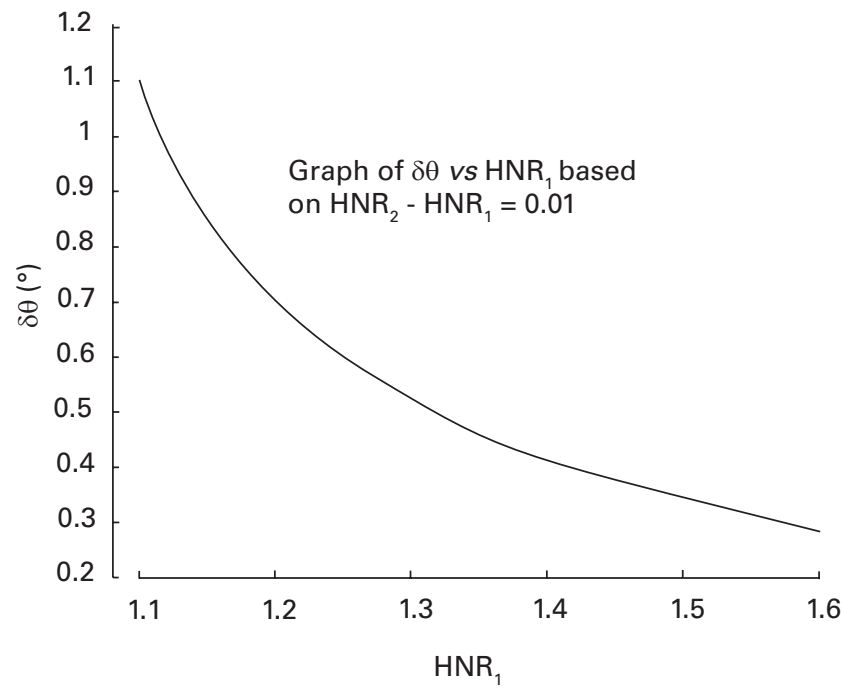

Fig. 4b

Figure $4 \mathrm{a}$ - relationship between head-neck ratio (HNR) and range of movement; $\delta \theta$ is the increase in angle before impingement occurs for $\mathrm{HNR}_{2}$ compared with HNR 1 . Figure $4 \mathrm{~b}$ - plot of change in $\delta \theta$ for 0.01 change in value of HNR.

increases the range of movement without impingement by about $10^{\circ}$ (Fig. 4).

Prior to hip resurfacing we found that women had a larger mean $\mathrm{HNR}$ than men $\left(\mathrm{HNR}_{\text {pre }}=1.33\right.$ and 1.24, respectively, $\mathrm{HNR}_{\mathrm{art}}=1.46$ and 1.33 , respectively). Other factors being equal, this would allow women to have about an $11^{\circ}$ greater range of movement without impingement than men.

As the neck size does not change during the operation, the reduction in HNR between pre- and post-operation is a manifestation of a reduction in the size of the head. In this series resurfacing reduced the size of the head by a mean of $3.7 \mathrm{~mm}$ when taking into account the thickness of the articular cartilage. The reason why the head size was smaller after hip resurfacing than before was probably due to the surgeon's desire to preserve acetabular bone (but without notching the femoral neck). The greater the pre-operative HNR, the more the head size could be reduced without notching the neck. This tendency to reduce the HNR more if the pre-operative HNR was high, is demonstrated in Figure 1.

During the follow-up period, both the HNR and the HJR increased significantly. As the size of the metallic head remained constant, these increases must be a manifestation of narrowing of the femoral neck. Post-operatively, the mean reduction of the narrowest part of the neck (assessed by HNR) was about $3.9 \%$, which is about $1.3 \mathrm{~mm}$. The mean reduction at the head-neck junction (assessed by HJR) was about $5.7 \%$, which is about $2 \mathrm{~mm}$.

The hips with a pseudotumour were different from the control hips in a number of ways. Pre-operatively and at 
follow-up/revision they had a higher HNR. However, postoperatively there was no difference in HNR. As a result, the changes between pre- and post-operative HNR and between post-operative and follow-up/revision HJR were greater for the pseudotumour group. This implies that in patients with a pseudotumour the size of the femoral head was reduced more at operation, and that subsequently more narrowing of the neck occurred. The differences were particularly marked and statistically significant in women, whereas in men they were not statistically significant. This might be because few men were included in the pseudotumour group, or because the aetiology and significance of HNR changes in men with a pseudotumour is different from those in women.

The data suggest that an important patient risk factor associated with pseudotumour formation is a very high head-neck ratio pre-operatively, which is more likely to occur in women. The main surgical risk factor is downsizing of the head in these patients with high $\mathrm{HNR}_{\text {pre, }}$ which can be easily done to retain acetabular bone stock, as there is very little risk of notching the neck. The average decrease in $\mathrm{HNR}$, including the cartilage layer, at the time of operation in women with a pseudotumour was about $0.17(11 \%)$, and the maximum was about $0.25(16 \%)$ (Table III). This equates to a mean downsizing of $5.5 \mathrm{~mm}$ and a maximum of $8.2 \mathrm{~mm}$, which would reduce the range of movement in the hip without impingement by a mean of $13^{\circ}$ and by a maximum of $21^{\circ}$. This would increase the likelihood of these patients impinging and edge loading their metal bearings.

The ROC analysis suggests that a useful threshold for predicting whether patients will develop a pseudotumour is a pre-operative HNR of 1.35 . The incidence of pseudotumour formation in patients with $\mathrm{HNR}_{\mathrm{pre}}<1.35$ was 3.4 times lower than in patients with $\mathrm{HNR}_{\text {pre }}>1.35$. However, pseudotumours still occur when the HNR is $<1.35$. A safer cut-off to use clinically may be 1.30 , as in this study no woman with an HNR of 1.30 or less developed a pseudotumour. In order to minimise the risk of pseudotumour formation we have previously suggested that surgeons should be cautious about resurfacing in women. ${ }^{10}$ We can now refine this advice to suggest that surgeons should be cautious about resurfacing in women with HNR > 1.3.

Reducing the size of the femoral head at operation was found to increase the risk of pseudotumour formation, with a reduction by $>5.3 \mathrm{~mm}$ in both genders increasing the risk 2.9-fold. On this basis we believe that the resurfacing head should be similar in size to the cartilage surface of the native head, and should not be more than $5 \mathrm{~mm}$ smaller. However, we have no evidence that retaining the head size will prevent pseudotumours from occurring in patients with a very high pre-operative HNR, who are at high risk for developing a pseudotumour, because all patients in our study with $\mathrm{HNR}_{\text {pre }}>1.35$ had downsized heads. Further observation will be required to investigate this point.

At follow-up, the HNR and HJR were generally larger and more variable in patients with a pseudotumour than in controls, which suggests that a pseudotumour may actually cause neck narrowing. An alternative explanation could be that the impingement that might be contributing to pseudotumour development also causes neck narrowing.

This study has a number of limitations, the main one being the small number of patients, particularly men. However, it is noteworthy that the majority of men who developed a pseudotumour had low $\mathrm{HNR}_{\text {pre }}$, whereas the majority of women had very high $\mathrm{HNR}_{\text {pre }}$, suggesting that the aetiology may differ between genders. The aetiology of pseudotumour is likely to be multi-factorial, yet in this study we have focused on one factor only. However, in both this and a previous study, ${ }^{17}$ which included most of the patients with a pseudotumour which we report here we found that the mean acetabular inclination and anteversion were similar in patients with a pseudotumour and controls, but the scatter was larger in those patients with a pseudotumour. In the previous study most patients with a pseudotumour had poorly positioned acetabular components. ${ }^{14}$ The patients with wellpositioned components who developed a pseudotumour did, however, all have pre-operative HNR > 1.30, supporting the concept of a multi-factorial aetiology.

This study has shown that patients whose pre-operative HNR is $>1.30$ and who have a marked decrease in HNR as a result of the resurfacing are at high risk of developing a pseudotumour. This high pre-operative HNR might permit a greater reduction in the size of the femoral component without notching the neck, which in turn increases the risk of impingement with edge loading, increased wear and pseudotumour formation.

This study was supported by DePuy Ltd (Leeds, United Kingdom), and financial support was received from the NIHR Research Unit into Musculoskeletal Disease, Nuffield Orthopaedic Centre and University of Oxford. The hip surgeons in the Oxford Hip and Knee Group are P. McLardy-Smith, R. Gundle, D. Whitwell, S. Glyn-Jones, C. Gibbons and A. Taylor.

The author or one or more of the authors have received or will receive benefits for personal or professional use from a commercial party related directly or indirectly to the subject of this article. In addition, benefits have been or will be directed to a research fund, foundation, educational institution, or other nonprofit organisation with which one or more of the authors are associated.

\section{References}

1. Amstutz HC, Beaule PE, Dorey FJ, et al. Metal-on-metal hybrid surface arthroplasty: two to six-year follow-up study. J Bone Joint Surg [Am] 2004;86-A:28-39.

2. Girard J, Lavigne M, Vendittoli PA, Roy AG. Biomechanical reconstruction of the hip: a randomised study comparing total hip resurfacing and total hip arthroplasty. $J$ Bone Joint Surg [Br] 2006;88-B:721-6.

3. Doherty SD. Does hip resurfacing restore normal range of motion and provide better joint motion than THR? Procs Orthopaedic Research Society 53rd Annual Meeting, Chicago, 2007.

4. Cheng Y, Wang S, Yamazaki T, et al. Hip cartilage thickness measurement accuracy improvement. Comput Med Imaging Graph 2007;31:643-55.

5. National Joint Registry. 5th Annual Report. http://www.njrcentre.org.uk/NjrCentre/Portals/0/Documents/England/Reports/5th\%20Annual.pdf 2008 (date last accessed 13 January 2010)

6. Stefen RT, Pandit HP, Palan J, et al. The five-year results of the Birmingham Hip Resurfacing arthroplasty: an independent series. J Bone Joint Surg [Br] 2008;90B:436-41.

7. Pandit H, Glyn-Jones S, McLardy-Smith P, et al. Pseudotumours associated with metal-on-metal hip resurfacings. J Bone Joint Surg [Br] 2008;90-B:847-51.

8. Hing CB, Young DA, Dalziel RE, et al. Narrowing of the neck in resurfacing arthroplasty of the hip: a radiological study. J Bone Joint Surg [Br] 2007;89-B:1019-24. 
9. Lilikakis AK, Vowler SL, Villar RN. Hydroxyapatite-coated femoral implant in metal-on-metal resurfacing hip arthroplasty: minimum of two years follow-up. Orthop Clin North Am 2005:36:215-22.

10. Glyn-Jones S, Pandit H, Kwon YM, et al. Risk factors for inflammatory pseudotumour formation following hip resurfacing. J Bone Joint Surg [Br] 2009;91B:1566-74.

11. Grammatopolous G, Pandit H, Kwon YM, et al. Hip resurfacings revised for inflammatoty pseudotumour have a poor outcome. J Bone Joint Surg [Br] 2009;91B:1019-24.

12. Kwon YM, Xia Z, Glyn-Jones S, et al. Dose-dependent cytotoxicity of clinically relevant cobalt nanoparticles and ions on macrophages in vitro. Biomed Mater 2009; 4:025018

13. Kwon YM, Glyn-Jones S, Simpson DJ, et al. Analysis of wear of retrieved metalon-metal hip resurfacing implants revised due to psuedotumours. J Bone Joint Surg [Br] 2010;92-B:356-61.

14. De Haan R, Campbell PA, Su EP, De Smet KA. Revision of metal-on-metal resurfacing arthroplasty of the hip: the influence of malpositioning of the components. $J$ Bone Joint Surg [Br] 2008;90-B:1158-63.
15. Langton DJ, Jameson SS, Joyce TJ, Webb J, Nargol AV. The effect of component size and orientation on the concentrations of metal ions after resurfacings arthroplasty of the hip. J Bone Joint Surg [Br] 2008;90-B:1143-51.

16. Langton DJ, Jameson SS, Joyce TJ, et al. Early failure of metal-on-metal bearings in hip resurfacings and large-diameter total hip replacement: a consequence of excess wear. J Bone Joint Surg [Br] 2010;92-B:38-46.

17. Grammatopoulos G, Pandit H, Glyn-Jones S, et al. Optimal acetabular orientation for hip resurfacing. J Bone Joint Surg [Br] 2010;92-B:1072-8.

18. Doherty M, Courtney P, Doherty S, et al. Nonspherical femoral head shape (pistol grip deformity), neck shaft angle, and risk of hip osteoarthritis: a case-control study. Arthritis Rheum 2008;58:3172-82

19. Krismer M, Bauer R, Tschupik J, Mayrhofer P. EBRA: a method to measure migration of acetabular components. J Biomech 1995;28:1225-36.

20. Zweig MH, Campbell G. Receiver-operating characteristics (ROC) plots: a fundamental evaluation tool in clinical medicine. Clin Chem 1993;39:561-77. 